\title{
Research on Legal Supervision of False News on WeMedia Network
}

\author{
Xiaoxun Huang \\ School of Public Administration \\ University of Electronic Science and Technology of China \\ Chengdu, P.R. China
}

\author{
Lijuan Huang, Xinyu Wang \\ School of Public Administration \\ University of Electronic Science and Technology of China \\ Chengdu, P.R. China
}

\begin{abstract}
In the information explosion age, many WeMedia operators always exagge rate the news facts deliberately in order to pursue the economic benefit, which causes more and more false information spread on the Internet by their own influence. Therefore, how to perfect the construction on administrative proactive supervision of WeMedia and administrative subsequent punishment system appears to be particularly important. In order to solve the problem of the incomplete legal supervision of WeMedia false news, it is required to establish the comple te legal system, improve the legislative technique, definite the relevant concepts and confirm the definition scope of false information published by WeMedia and the administrative subject scope which has the specific jurisdiction. In view of the ineffective supervision of the main body of administrative law enforcement and the repeated prohibition of false information released by the media, it is necessary for the administrative organ to assume corresponding regulatory responsibilities, increase the punishment for the default of adminis trative staff, and at the same time, through the laws and regulations, the management and joint responsibility of the self-media platform. It is confirmed that the administrative sanctions against WeMe-media violations should be strengthened according to the law, and the state-organized training and assessment of self-media supervision mode should be established to further improve the entry barriers for WeMedia practitioners.
\end{abstract}

Keywords-WeMedia; False news; Administrative legislation; Supervision

\section{Development status of WeMedia}

According to the opinions of Sheppelman and Chris Willis, WeMedia is "a kind of method to understand that how the public provide and share their own facts and news by strengthening the digital technology and associating with general public and global knowledge system ${ }^{[1]}$." Till now, the overall trend has the following features: the first is the subject universality. The leap of information technology and digital media makes the public can interact and share at the short range on the Internet. Because everyone can create, publish, spread and receive news based on their own interests and hobbies, WeMedia has its own mass base to provide the platform for citizens to express opinions equally with free contents and no limit on time and space; the second is innovation. The overall WeMedia environment is free, which can attract the public by editing the same news to many forms according to their own creation and personality, therefore, different WeMedium have different attentions; the third is timeliness. It is easy for WeMedia to publish news, which is

Support by 2016 University of Electronic Science and Technology of China Central University Basic Research Business Fee (Critical

Academy) Basic Research Project convenient for public to know and grasp the dynamic development of news at once and pay the timely attraction; the forth is diversity of publishing forms. The network technique development brings the continuous update on WeMedia forms, such as personal homepage, blog, e-mail, QQ and microblog, which are all the WeMedia platform with wide range of target audience.

With the rapid development of news from the WeMedia, the interactive enthusiasm of people participating in social hotspot discussions has been continuously improved, but there are still many problems in the operation process. Firstly, the professional literacy of news WeMedia operators is uneven. Since WeMedia operators only need to upload their own ID card number, telephone and photo with ID card on hand, the audit will be approved after the form review and agreement of the staff of the WeMedia platform. These WeMedia operators are mostly amateur journalists or company teams, who have low professional quality on news and limited information collection capacity. In order to achieve the drainage effect, they always edit the news with their personal emotions, which will affect to masses' objective judgment on news contents. Secondly, there is too much false news which is short of the effective supervision. The news WeMedia is different from the traditional media, whose news acquisition source, interview jurisdiction and information volume of follow-up reports are all limited. The low standards of entry barriers and the lack of administrative supervision have led to doubts about the authenticity of the news published by the relevant administrative departments. The clarification of the news by the relevant administrative departments is limited in scope and lack of administrative punishment and punishment, which makes the false news flooding and indirectly affects the government's execution.

The social issue about false news by WeMeida that has truly entered the public's view is Lei Yang Case known by all people in 2016. Many WeMedium spread various kinds of ideas and reports without any facts before the prosecutor got involved and the official autopsy report result didn't come out. The reports were confirmed to be false news afterwards. The numerous false rumors lead to a variety of suspicions from the society about the judicial credibility. Afterwards, there was no damage on WeMedia who spread false information, and the platform also was not involved, but it is difficult to make up the crisis of confidence to the judicial credibility. Nowadays, since the WeMedia has been updated a lot, the regulatory authorities have taken on more severe regulatory responsibilities. In order 
to develop the healthy and orderly WeMedia, Cyberspace Administration of China updates the typical cases that WeMedia spreads the harmful information on the Internet, and provides the relevant administrative punishment to those which affected the guidance of public opinion and spread negative information: from appointment, special rectification meeting, stopping operation to shut down the account.

\section{WMEDIA SUPERVISION AND LEGISLATION STATUS}

By contrast, there are various governance forms of publishing and spreading false news by WeMedia, but the government supervision is mainly according to law and the industry autonomous standards is supplement. Taking U.S. as an example, it confirms the legal liability of those who published false news by the legislation in the news field. The legislation system includes "Telecom Law", "Anti-Spam Law" and "Child Online Protection", with wide law ranges, the accountability mechanism of relevant administrative departments is also relatively complete. [2]While the legal system has been continuously improved and government supervision has been continuously strengthened, self-discipline organizations and industry norms have emerged from the WeMedia industry, and individual supervision of WeMedia inspectors has been established, forming a relatively mature self-media news supervision and accountability system. Germany has conducted detailed research on the network field. As the first country in the world to formulate a network statute law, it legally confirms the rationality of the principle of "going into freedom", but strictly sets the threshold for entry from the WeMedia. To improve the enforcement of the law, the government administrative department adopts the "post-event review" measures after the media enters the platform, and implements hierarchical management of the news release [3]. After the illegal facts occur, the relevant departments prescribed by the law impose administrative penalties on them.

When referring to the relevant abroad experience, China is also exploring the supervision methods to renovate the false news by WeMedia. Temporary provisions about management that websites work on publishing news and Provisions of E-notice service management on the Internet require that non-legally registered news units or electronic bulletin providers may not engage in the business of posting or reprinting news or electronic announcements. Authentic news is regulated to prevent the proliferation of false news. At the same time, Provisions of Internet users' public account information service management and The cyber security law of the People's Republic of China stipulate that Internet users' public account information service providers should formulate and publicize management rules and platform conventions, sign service agreements with users, and clarify the rights and obligations of both parties. To prevent the spread of false news in the two dimensions before and after, they require the WeMedia account operators to provide the true ID information and professional aptitude, and the information provider to bear the responsibility of the WeMedia to publish false news supervision on its platform. Besides, Decision of the Standing Committee of the National People's Congress on preserving computer network security adopted in 2000 requires relevant departments to punish perpetrators for their behaviors of starting a rumour, slandering or publishing and spreading harmful information on the Internet, and guides the new WeMedia to utilize the Internet correctly. Since the implementation of the Internet Publishing Service Management Regulations on March 10, 2016, the media industry has been further standardized. According to the provisions of Article 9 of the Law, in order to obtain a network publishing license, in addition to meeting the requirements for filing and licensing, it is necessary to improve the improve the company's professional staff and evaluate the title as a business unit. It is the first time that China's legislation regulates the professionalism of employees, which not only brings great challenges to Internet startups, but also further promotes the professionalization of network platforms. Generally speaking, China has regulated itself in the form of regulations and decisions, but it still lacks a complete system of WeMedia administrative legislation.

\section{Problems and countermeasures of China WeMedia SUPERVISION}

In the WeMedia age, there are many systems about the network false news supervision which need to be constructed and optimized further in China.

At present, the main problems are as follows: firstly, the legislation hierarchy is insufficient; the legislation contents are not complete. The first is that Press Laws system has not been formed, the legislative level is too low, the single-line regulations are too numerous, and the content is complex; the second is that the definition scope and detailed admittance threshold of "WeMedia false news" are not confirmed by legislation yet; the third is that the law enforcement level is not high. Except for the imperfection of the legal system, it is difficult to enforce the law. The lack of administrative supervision and punishment mechanism in the relevant administrative departments is also the reason for the low efficiency of claw enforcement; the forth is that it is difficult to confirm the joint liability of Internet platforms. Under this circumstance, the platforms shall assume the certain responsibility with WeMedia. However, Chinese laws and regulations have few provisions on the joint responsibility. The fifth is that there are no relevant provisions on how to manage the special WeMedia subjects such as personal public accounts and personal Microblog users.

Secondly, the ambiguity of the administrative law enforcement body and the unclear scope of supervision have led to weak supervision. The first is that the law enforcement subject is obscure and the provisions are not clear enough. Internet Information Service Management Methods stipulate that the departments of news, publishing, education, sanitation, industry and commerce, public security and national security can supervise and manage the Internet information contents in their respective scopes of liability, resulting in multiple administrations. The departments all have law enforcement authority, and the law does not stipulate that multi-sectoral cooperation or a single department can blame the false news released from the WeMedia. The second is that the subject scope and punitive measures of administrative law enforcement are not clear, although Internet Information Service Management Methods has proposed to submit the non-operating Internet information service in 2000. Internet 
Publishing Service Management Regulations mentioned in 2016 in details that "those who provide the news information service activities to public and open the public accounts shall apply for the aptitude approval first and put on records to the local office”, this is not only aimed at the private WeMedia, the wechat public account and Microblog on behalf of government also need to be filed. [4] On May 2nd, 2017, the national Internet information office published the new Internet News Information Service Management Provisions, which developed and replenished Internet News Information Service Management Provisions implemented in 2005. But it doesn't indicate clearly that whether the network platform or the personal account needs to be approved, it doesn't mention the platform supervision to the personal WeMedia. There are still no explicit provisions on WeMedia supervision subject scope. At the same time, as for the enterprises which don't meet the standard and the network platform which don't obtain the network publishing license, there are no detailed punishment measurement and executive institutions stipulated. The third is that the administrative supervision and law enforcement are not in place. In the process of administrative supervision, the detailed supervision scope of each department doesn't be clarified in the stage before event, which causes the false news can't be supervised by the relevant departments in time. In the post-event stage, the release of false news from the WeMedia may still appear in the public eye after being subjected to administrative punishment, and the relevant administrative departments will continue to supervise it. But in the WeMedia age, with the Soviet Union's dissolution, although England and U.S. Developed this system, the implementation intensity in China is not enough. The current administrative penalties in China are relatively light, and the sole responsibility of the responsible person is the unqualified business qualifications, the lack of compliance with the news sources, and the imperfect filing procedures stipulated in "Temporary Provisions of Publishing Service Website Management” and "On-line Publishing Service Management Regulations". Such administrative punishments are mostly based on warnings, disqualifications, fines, which have limited efforts to rectify WeMedia information. It doesn't be defined as the legal system explicitly all the time, as well as be effective to punish the major principals. The enforcement of administrative agencies is inefficient.

In order to solve the imperfect supervision and legislation on the false news of WeMedia, it is necessary to establish a complete law system. At first, the government should improve the legislation technique and definite the law concepts, and confirm the definition scope of "WeMedia false news". The laws should clearly stipulate the scope of supervision of the main body of media administration, the administrative department of specific jurisdiction, and further improve the administrative supervision of the United Kingdom and the United States in the administrative supervision of multiple fields. In the case of administrative supervision involving multiple fields, when multiple administrative departments have law enforcement authority, the law should clearly stipulate that multiple departments cooperate or a single department can publish the WeMedia for spreading the false news.
As for the obscure administrative law enforcement subject and inadequate supervision, in the pre-event stage, the departments and staff who have not fulfilled their relevant duties in administrative supervision shall be subject to accountability to improve the efficiency and enthusiasm of administrative law enforcement departments for the supervision of false information. In the post-event stage, the administrative sanctions against the WeMedia will be increased, and the rectification will be carried out from the source to increase the illegal cost. The law enforcement agency carries out the provisions of punishment on the platform joint liability further, and the publishing platform needs to assume more management liability. The supervisory authority shall supervise the establishment of the corresponding editor-in-chief from the media communication platform, and actively promote the editor-in-chief to review the corresponding information published by the WeMedia and establish a joint liability system. The inadequate platform supervision also shall assume the joint liability with WeMedia, which requires the platform to strengthen the supervision consciousnes. The main responsibility of platforms is to check the identity and aptitude of the account, classify and put on records, mark different signals for different types of accounts, implement and manage by the departments which issue the license by different management methods; the Party and government offices, enterprise and public institutions and all kinds of mass organizations shall issue the public accounts, and manage them in accordance with the provisions of the State Organization Law and Information Release; other accounts shall be managed in accordance with the "Internet Information Service Management Methods". As for the relevant employees in WeMedia platforms, the law enforcement institutions shall improve the admittance threshold successively, which gradually form the system that only those who obtained the press cards can spread and report relevant news. The WeMedia employees need to undergo corresponding training and assessment by the state organization, and they can obtain the corresponding qualification certificates issued by the State Administration of Radio, Film and Television.

\section{CONCLUSION}

With the further popularization of Internet technology, WeMedia has gradually become the main channels for public to touch with news. Due to the excessive pursuit of timeliness and attention from the media, it has led to the publication of false news without verifying the accuracy of the news, resulting in widespread dissemination of false news and, to a certain extent, social disorder. In terms of laws and regulations, there is a lack of access threshold and administrative enforcement basis. It is difficult for the relevant administrative departments to carry out administrative supervision on them, and it is impossible to give corresponding administrative penalties to WeMedia operators, resulting in the false news situation not to be solved yet. It is an inevitable choice to improve the threshold of self-employment from the media and improve the relevant administrative law system in the form of law. 


\section{REFERENCES}

[1] Kai Wang, Discussion on legal regulations of WeMedia, [J] Jiangxi Normal University, 2013 In Chinese

[2] Dongmei $\mathrm{Mu}$, Legal regulations of network false news, [J] Shanghai Normal University, 2016 In Chinese
[3] Yang $\mathrm{Mu}$, Analysis on civil tortious liability for network platform providers, [J] Oriental IAW, Phase 3rd of 2017 In Chinese

[4] Jintong Zhang, Suzhen Cao On regulating network news title in "title reading age" [ $\mathrm{J}]$ Journal of Hebei University of Economics and Business (Comprehensive Edition) Phase 4th of 2016 In Chinese 